\title{
Gênero e Participação Feminina no Tráfico de Drogas na Cidade de Ponta Grossa, Paraná
}

\author{
Gender and Women's Participation in Drug Trafficking in Ponta Grossa - Paraná - Brazil
}

\author{
Karina Eugenia Fioravante \\ Universidade Estadual de Ponta Grossa \\ karina_frr@hotmail.com \\ Joseli Maria Silva \\ Universidade Estadual de Ponta Grossa \\ joseli.genero@gmail.com
}

\begin{abstract}
Resumo
A criminalidade feminina é um fenômeno em ascensão no Brasil e também a participação feminina no tráfico de drogas. Utilizando as perspectivas feministas da Geografia, objetivamos compreender de que forma a experiência feminina é representada no tráfico de drogas a partir do espaço carcerário. Nossa fonte de dados foram entrevistas realizadas com as detentas do Mini Presídio Hildebrando de Souza, em Ponta Grossa, Paraná, os dados do Programa Pró-Egresso e do Departamento Penitenciário Nacional. Concluímos que as mulheres envolvidas com o tráfico de drogas encontravam-se em situação de vulnerabilidade e, na tentativa de conseguir outras estratégias de sobrevivência, se viram envolvidas na dinâmica do tráfico de drogas.
\end{abstract}

Palavras - Chave: Gênero, tráfico de drogas, mulheres.

\begin{abstract}
Female criminality is a rising phenomenon in Brazil, as well as women participation in drug traffic. Recurring to the ideas of Feminist Geography, we aim to understand how the feminine experience is represented in the drug traffic from the space of jail. Our data sources were interviews made with the prisoners of the Public Jail Hildebrando de Souza, in the city of Ponta Grossa, the data collected in the Pró-Egresso Program and the data provided by the National Penitentiary Department of Brazil. We concluded that the women involved in drug traffic have found themselves in a vulnerable situation, and, in an attempt to achieve way of survival, they got involved in drug traffic.
\end{abstract}

Keywords: Gender; drug traffic; women. 


\section{Palavras Iniciais}

A criminalidade vem crescendo expressivamente em nosso país, trazendo à Academia uma nova necessidade: a de se discutir um tema até então ignorado. Uma forma de comprovarmos o aumento da criminalidade no Brasil é observando, também, o aumento do número de pessoas encarceradas. Fazendo uma sucinta comparação, no ano de 2000, segundo dados do Departamento Penitenciário Nacional (DEPEN), estavam presas no Brasil, 232.755 pessoas e até junho de 2009, a população nacional encarcerada era de 469.807 detentos, em cadeias e penitenciárias. A população carcerária dobrou em apenas uma década.

Especificamente, a criminalidade feminina também é fenômeno em ascensão no Brasil e ainda é tema pouco discutido na Academia, especialmente na ciência geográfica. Os dados fornecidos pelo Departamento Penitenciário Nacional (DEPEN, 2008) mostram que apesar de existir uma grande diferença entre o universo masculino e feminino, o número de mulheres encarceradas cresce expressivamente no Brasil. Em quase dez anos, a população encarcerada feminina cresceu mais de $300 \%$. No ano de 2000 , eram 3.240 mulheres presas e no ano de 2009 , o número saltou para 10.171. Ainda de acordo com o DEPEN (2007), a população encarcerada feminina no Brasil cresceu mais de $37 \%$ nos últimos quatro anos, um crescimento anual de mais de $11 \%$. Estima-se que em 2012, as mulheres representarão $7.65 \%$ do total de presos no Brasil, sendo que atualmente representam 6,12\% do total (DEPEN, 2009).

A pesquisa realizada nos arquivos do Programa Pró - Egresso, o qual tem por função a prestação de auxílio e acompanhamento às pessoas saídas do cárcere e às que cumprem penas restritivas de direito, mostrou que, durante os anos de 2000 a 2007, o número de mulheres em conflito com a lei cresceu 527\%. Quando foi realizada a análise dos delitos cometidos pelas mulheres egressas, ou seja, as que estavam internadas no sistema carcerário, percebeu-se que 30\% estiveram encarceradas por envolvimento com entorpecentes. Atualmente, na cidade de Ponta Grossa, Paraná, estão encarceradas cerca de 70 mulheres vivendo em condições precárias e de super lotação. Em trabalho de campo realizado no Mini Presídio Hildebrando de Souza, onde estão internadas as mulheres, percebemos que das 65 mulheres encarceradas, as quais responderam nosso questionário, 53 delas estavam na prisão indiciadas pelo artigo 33 da Lei dos Antitóxicos, ou seja, por tráfico de drogas.

Assim, esse trabalho tem por objetivo discutir a relação entre o tráfico de drogas e a mulher, a partir das falas de 17 mulheres encarceradas na cidade de
Ponta Grossa - Paraná. Primeiramente, trazemos uma reflexão sobre os conceitos que nos apoiaram na construção de nossa discussão teórica, ou seja, o fenômeno do tráfico de drogas, gênero e criminalidade feminina. Finalizamos nossa reflexão apresentando quais são as representações que as mulheres encarceradas têm sobre a participação feminina na dinâmica do tráfico de drogas.

\section{Uma Discussão sobre Criminalidade Feminina, Tráfico de Drogas e Gênero}

Todas as relações sociais são espaciais, e, portanto, impossíveis de serem compreendidas fora de sua espacialidade (SANTOS, 2008). Cada vez mais, as/os geógrafas/os feministas vêm se empenhando em demonstrar que essas relações socioespaciais também são permeadas por especificidades de gênero. A criminalidade, entendida como um fenômeno social e espacial, se apresenta da mesma forma.

A criminologia começa a chamar à atenção da Academia por volta da década de 1970, mas surge com o trabalho de Cesare Lombroso, intitulado: O homem delinquente, de 1876 (MISSE, 1995a). Lombroso acreditava que existiam na sociedade criminosos natos, ou seja, o verdadeiro criminoso, aquele que cometia crimes repetidamente ao longo de sua vida, apresentava características pessoais que o caracterizava como tal. Segundo o autor, os criminosos sofriam de uma anomalia atávica, ou seja, seu biótipo físico os distinguia do resto da sociedade. Com o crescimento acentuado da criminalidade nas últimas três décadas e com a escassez de trabalhos sobre o tema, muitos cientistas têm se perdido na defesa de teorias antigas e que não mais dão conta de explicar esse fenômeno de forma satisfatória. Como nos lembra Oliveira (2008), as relações humanas são dinâmicas, sendo assim, a ciência, em especial as ciências sociais, entre as quais, a Geografia, vê a necessidade de acompanhar o ritmo imposto por novas realidades sociais e urbanas.

Com as provocações e inovações trazidas por Michel Foucault em sua primeira viagem ao Brasil em 1973, ocasião em que o filósofo mostrou os manuscritos que se tornariam o prestigiado 'Vigiar e Punir', surge aos cientistas sociais à necessidade de serem inovadas, ou ao mínimo, repensadas as então teorias defendidas e aplicadas. Vários trabalhos surgiram então, já apresentando uma forte influência foucaultiana, como Ramalho (1976), Abreu (1980), Pinheiro (1983) e Paixão e Campos (1983).

A grande dificuldade que ainda encontramos em trabalhos que abordam os temas acerca da 
criminalidade é o apego a certos argumentos pouco satisfatórios, como por exemplo, a relação entre pobreza e criminalidade. Ao discutir essa associação, Souza (1998) espera esclarecer que a relação entre esses dois fenômenos não pode ser feita de forma simplista e superficial. Nas palavras do autor:

Se a correlação entre pobreza e criminalidade fosse positiva e tão forte assim, as grandes metrópoles da Índia estariam entre as mais violentas do mundo por razões socioeconômicas, o que não é o caso. $\mathrm{O}$ filtro ou a mediação da cultura (e da conjuntura política, das instituições etc.) não pode ser subestimado. Uma tal associação entre pobreza e criminalidade, se simplista, pode ser, além de errônea, preconceituosa, por passar a ideia absurda de que só os pobres são criminosos. A lembrança nãosimplista de uma conexão entre injustiça social e criminalidade visa, porém, a recordar que as condições materiais, sob determinadas circunstâncias culturais e institucionais, podem atuar como fator de estímulo a estratégias de sobrevivência ilegal, com consequências nefastas para o conjunto da sociedade e para os próprios pobres (riscos altos, ganhos pequenos...). Com isso, crê-se evitar tanto o reducionismo economicista de esquerda quanto os vieses institucionalista e culturalista de certas abordagens sobre a criminalidade (SOUZA, 1998, p. 3).

Na mesma perspectiva, Misse (1995a) critica o imaginário social construído que conecta instantaneamente pobreza à criminalidade. Uma coisa é inegável, a grande maioria das pessoas que se envolvem com crimes são provenientes grupos de baixa renda. Em pesquisa realizada com as mulheres egressas do sistema penitenciário na cidade de Ponta Grossa-PR no ano de 2008, observamos que, de um universo total de 57 mulheres, $75 \%$ não possuíam renda própria ou tinham renda mensal de até $\mathrm{R} \$$ 400,00 reais mensais.

Um elemento é consenso entre os estudiosos da criminalidade: o crime não é um privilégio de classe (MISSE, 1995b). Ainda, é impossível negar a correlação existente entre certos tipos de crime com determinadas classes sociais. Os chamados 'crimes de pobre', caracterizados por meios mais violentos como roubo, homicídio e lesão corporal entre outros, estigmatizam o indivíduo em proporções muito maiores do que os 'crimes de rico' ou 'de colarinho branco', caracterizados geralmente como estelionato e corrupção. Nesse sentido, o tráfico de drogas tem sido comumente associado com as classes mais baixas de nossa sociedade, especialmente com os morados de favelas e morros.

Souza (2000) trabalha com a dimensão espacial do tráfico de drogas, discutindo a hierarquia existente nessa dinâmica, bem como as implicações sociais dessa prática para a sociedade. $\mathrm{O}$ autor discute que $\mathrm{o}$ tráfico de drogas e o aumento da criminalidade urbana não devem ser entendidos como sinônimos, mas ao mesmo tempo, não se deve deixar de lado a ligação existente entre esses dois fenômenos.

O tráfico de drogas é, hoje, um dos negócios mais rentáveis do mundo, apresentando características próprias que o colocam em paralelo com o mercado de trabalho. Souza (2000) discute a hierarquia espacial e a divisão do trabalho existente na dinâmica do tráfico de drogas. Segundo o autor, essa divisão que envolve diversos atores sociais é organizada através de relações de poder, na medida em que cada ator possui uma participação diferente nos ganhos do negócio.

Com as discussões feministas na Geografia, surgem novas possibilidades metolodológicas e conceituais, bem como novas temáticas, até então invisíveis. Badinter (2005) discute a criminalidade feminina e a dificuldade que as feministas encontram frente à temática. Possivelmente por colocar em dúvida a premissa de que as mulheres são seres frágeis e indefesos, pesquisar aspectos como a criminalidade seja tão difícil para as pesquisadoras feministas. A autora discute de forma honesta a violência cometida por mulheres e nos lança o desafio de por ao lado a segurança que a vitimização confere às mulheres $\mathrm{e}$ encarar esse fenômeno com maturidade, questionando se a violência feminina é uma resposta a dominação masculina, ou se ela simplesmente pode ser genuína.

Para Badinter (2005) tanto nos períodos de extrema violência, como genocídios e massacres, quanto no cotidiano, às mulheres podem, sim, tornarem-se violentas, ou seja, matam por interesses próprios ou sadismo. Sendo assim, a tentativa de explicar a violência feminina trazendo à culpa a dominação masculina é uma forma falida e pouco, ou nada, contribui para a 'libertação' das mulheres. Muito pelo contrário, apenas perpetua a visão indefesa e angelical das mulheres, visão esta que vem sendo utilizada há muito tempo como justificativa para a 'demonização' da sexualidade masculina.

A autora conclui que:

Ao querer ignorar sistematicamente a violência e o poder das mulheres, ao proclamá-las constantemente oprimidas e, 
portanto, inocentes, traça-se em negativo o retrato de uma humanidade cindida em dois e pouco conforme a verdade. De um lado, as vítimas da opressão masculina, do outro, os carrascos onipotentes. Para lutar contra essa situação, vozes feministas cada vez mais numerosas investem contra a sexualidade masculina, apontada como a raiz do problema. Ao fazê-lo, elas delineiam os contornos de uma sexualidade feminina em contradição com a evolução dos costumes e redefinem uma 'natureza feminina' que acreditávamos esquecida (BADINTER, 2005, p. 92).

Quando analisamos a criminalidade feminina utilizando o conceito de gênero como elemento metodológico, temos uma perspectiva crítica capaz de dar inteligibilidade à aceitação desse fenômeno por parte da população. A identidade feminina está sobrecarregada de estereótipos construídos culturalmente, os quais constrangem a sociedade a esperar certas atitudes e determinados papéis preestabelecidos quanto ao 'ser mulher'. Da mulher se esperam a passividade, a gentileza e a docilidade, 'qualidades' estas nem sempre acentuadas e facilmente perceptíveis nas mulheres envolvidas no ambiente criminal e mesmo nas reclusas em penitenciárias e cadeias.

Essa bipolaridade que opõe características masculinas e femininas foram construídas pela sociedade e se naturalizaram como essências dos seres de diferentes sexos. Contudo, é importante marcar que a noção de naturalização dos corpos em sexos opostos possui uma dinâmica social a ser analisada.

$\mathrm{O}$ conceito de gênero aparece assim, como importante ferramenta conceitual, metodológica e também política, proporcionando uma nova leitura da realidade socioespacial. Silva (2004) discute que a utilização do conceito de gênero como ferramenta explicativa confere uma análise mais complexa e profunda do espaço geográfico, pois traz elementos ignorados pela Geografia tradicional, como o papel da mulher na produção do espaço, por exemplo.

Para esse trabalho, utilizamos as ideias de Silva (2005) acerca da potencialidade do conceito de gênero para a ciência geográfica. A autora discute que o conceito de gênero traz consigo valiosos elementos de pluralidade e multidimensionalidades, englobando aspectos esquecidos pela ciência geográfica. Entendemos o conceito de gênero enquanto uma representação, e sendo assim, diferenciado temporal e espacialmente. $\mathrm{O}$ espaço é permeado por relações de gênero, sendo estas, ressignificadas e reelaboradas nas relações socioespaciais cotidianas.

As desigualdades de gênero podem explicar a dificuldade que nossa sociedade ainda tem na aceitação da criminalidade feminina. É muito comum notar o escândalo da população quando alguma mulher está envolvida em algum crime de natureza bárbara, ou os chamados crimes hediondos. Para a maioria da população, a mulher infratora é aquela que, em um momento de histeria, espanca os filhos, ou mais comumente, agride o marido por motivos de ciúmes.

Trabalhar com campos científicos que não estão consolidados e que ainda geram polêmicas no mundo acadêmico nos traz alguns desafios. Além da sensação de angústia e medo em determinados momentos, a motivação é muito maior quando fazemos uma coisa ainda não feita. Olhar o mundo através de outras lentes, descobrindo e trazendo à tona suas particularidades e especificidades, é maravilhoso, especialmente para uma/um pesquisadora/or. As perspectivas feministas da Geografia vêm se aprimorando cada vez mais para dar conta das novas necessidades teóricas e metodológicas, pois nossa sociedade é dinâmica, e o mesmo espera-se da ciência. A questão da criminalidade feminina é uma delas. Historicamente ignorada e negligenciada acadêmica e socialmente, esse fenômeno vem tirando o sono de muitos corajosos pesquisadores que se engajaram com a área.

Uma pergunta se faz crucial: como estudar o fenômeno? Existe - ou deveria existir - uma maneira particular para se analisar a criminalidade feminina? Qual o problema metodológico em torno da questão da criminalidade feminina? Nossa perspectiva é de que, a partir do momento em que ignoramos as especificidades de gênero, corremos o risco de cair em uma armadilha um tanto quanto corriqueira. Ou seja, negando-se a necessidade de um recorte epistemológico específico estamos ofuscando importantes aspectos culturais e ideológicos que podem ser decisivos na análise do cometimento de determinados crimes.

Pimentel (2008a) nos lembra que foi Lombroso o primeiro a abrir espaço para o estudo das mulheres criminosas, particularmente em sua obra intitulada $L a$ Donna Delinquente. Essa análise deixa a desejar, considerando que seu forte cunho biológico determinista, deixa de lado aspectos culturais de subjetividade. Na mesma perspectiva, Soares e Ilgenfritz (2002) resgatam as problemáticas limitações que as primeiras teorias feministas apresentavam. Nas palavras das autoras:

A base das explicações biopsicológicas dos pensadores da virada do século XX residia 
na noção de uma influência dos 'estados fisiológicos' pelos quais passaria a mulher nas fases da puberdade, da menstruação, da menopausa, do parto (estado puerperal) período em que estaria propensa à prática de crimes. Durante a vigência desses fenômenos biológicos que atingem o corpo da mulher, ou seu estado psicológico ficaria alterado pela irritabilidade, instabilidade e agressividade (SOARES e ILGENFRITZ, 2002, p. 64).

As palavras de Soares e Ilgenfritz (2002) nos deixam claro que, mesmo de forma intencional, as teorias feministas acabam encontrando um caminho para a vitimização feminina. Quando jogamos a culpa em destemperos biológicos e psicológicos, estamos escondendo um fato certeiro: as mulheres, assim como os homens, cometem crimes por interesse próprios e em plena consciência disso. Na mesma perspectiva, é muito interessante que, comumente, associa-se às mulheres crimes que estão intimamente ligados à espacialidade doméstica e maternal, ou seja, o aborto e o infanticídio.

Souza (2006) discute que historicamente a identidade feminina tem sido associada à esfera privada. Na mesma proporção, a esfera pública, ou seja, o espaço do político e do conhecimento era resguardado aos homens. A autora discute que na medida em que a vida privada da mulher começou a se tornar cada vez mais politizada, houve a migração das mulheres também para os espaços públicos, tornando assim visíveis aspectos de sua vivência que até então eram ignorados.

Ocorre assim, um redimensionamento dos papéis femininos na sociedade, ou seja, a mulher passa a viver espacialidades até então exclusivamente masculinas, como o mercado de trabalho, por exemplo. É interessante atentar para o fato de que esse processo ainda está em construção. Torna-se, assim, importante desconstruir a falsa imagem de que a casa e a vida familiar são as únicas espacialidades de existência cotidiana de mulheres.

Nessa perspectiva, Souza (2006) lembra que o preconceito e a desigualdade de gênero ainda permanecem especialmente no sentido das mulheres terem menos condições de inserção no mercado de trabalho, conseguindo assim, geralmente cargos subalternos e com baixa remuneração, ou em situações extremas, em atividades irregulares e ilegais. A autora conclui:

Não queremos dizer com isso que a motivação das mulheres para praticar um crime se encerre apenas nas privações socioeconômicas, nem vincular mecanicamente a pobreza à violência. $\mathrm{O}$ que queremos é chamar a atenção para o maior grau de vulnerabilidade das mulheres pobres, sua exposição maior ao atrativo de ganho fácil exercido pelo mundo do crime. Nesse sentido, pesariam tanto a necessidade da mulher em prover seu próprio sustento como sua crescente responsabilidade na manutenção da família, fazendo com que a busca por alguma forma de rendimento se torna premente. Com a necessidade de se garantir o presente, limitam-se as expectativas para o futuro e prioriza-se o imediato - o que pode facilitar, sobretudo no caso das mais pobres e desamparadas, o envolvimento em atividades criminosas e lucrativas em curto prazo (SOUZA, 2006, p. 13).

Concordamos com a autora quando ela defende que, muitas vezes, as mulheres vivem em situação de vulnerabilidade espacial, ou seja, suas vivências cotidianas, muitas vezes restritas a vilas de baixa renda as tornam muito mais vulneráveis ao ato criminoso. Nossa perspectiva não é de vitimização, muito pelo contrário, acreditamos que adotando essa postura estamos corroborando com as desigualdades de gênero, afirmando a posição subalterna da mulher. Entretanto, é possível defender com segurança que essas mulheres são desassistidas pelo poder publico, e sem outras alternativas de ganho, procuram meios mais fáceis para obter seu sustento. Fazemos uma ressalva nesse momento, no sentindo de não corroborar o mito de que todas as pessoas de baixa renda são marginais ou criminosos.

As perspectivas feministas são plurais, permeadas por disputas políticas, culturais e ideológicas. Ou seja, não existe um feminismo e sim vários, cada qual dialogando com os estudos criminológicos de maneiras específicas. $\mathrm{O}$ que não podemos negligenciar é que, na medida em que as perspectivas feministas são utilizadas como uma possibilidade metodológica, a própria metodologia criminológica em si cresce. Aí se encontra a importância de estudos que busquem compreender as práticas cotidianas de mulheres criminosas.

Passamos agora para a segunda parte de nossa reflexão, na qual discutiremos a participação feminina na dinâmica do tráfico de drogas na cidade de Ponta Grossa-Paraná. Utilizaremos para tanto, entrevistas que realizamos com dezessete mulheres encarceradas no Mini Presídio Hildebrando de Souza. Nosso 
questionário de entrevista não visava somente à relação entre a mulher infratora e o tráfico de drogas, entretanto, obtivemos um grande número de evocações relacionadas a essa prática criminosa, seja relacionada ao motivo da prisão em si, seja relacionada a toda construção da espacialidade de vivência dessas mulheres antes do encarceramento.

\section{A Participação Feminina na Dinâmica do Tráfico de Drogas}

Segundo dados do Ministério da Justiça, encontravam-se presas no Brasil no ano de 2009, 4.451 mulheres por tráfico de entorpecentes e outras 186 por tráfico internacional. De acordo com o Departamento Penitenciário Nacional (DEPEN), até junho de 2009, estavam presas no Estado do Paraná 334 mulheres por envolvimento com drogas, sendo 310 delas por tráfico de entorpecentes (artigo 12 da Lei 6.368/76 e artigo 33 da Lei 11.346/06) e o restante, 24 por tráfico internacional de drogas (artigo 18 da Lei 6.368/76). O relatório disponibilizado pelo DEPEN no ano de 2007 mostrou que $43,75 \%$ das mulheres estrangeiras que estão presas no Brasil, se encontram nessa situação por crime de tráfico de drogas.

Na cidade de Ponta Grossa - Paraná observamos que $88 \%$ das mulheres encarceradas no Mini - Presídio Hildebrando de Souza foram presas por envolvimento com entorpecentes. Esse dado se apresenta de forma muito interessante, uma vez que $82 \%$ delas também afirmaram não serem usuárias de nenhum tipo de droga. O que queremos demonstrar é que a participação feminina na dinâmica do tráfico de drogas é um fenômeno em ascensão no Brasil, necessitando, portanto, da atenção dos pesquisadores engajados com os estudos criminológicos, bem como cientistas em geral.

Anteriormente já foi discutida a hierarquização socioespacial presente no tráfico de drogas (SOUZA, 2000). Cada vez mais, as mulheres vêm se encaixando nessa dinâmica, tanto em papéis subalternos quanto em posições de maior poder. Uma forte corrente de estudiosos comprometidos com a temática defendem que o envolvimento das mulheres com as drogas se deve geralmente ao laço afetivo que elas possuem com homens traficantes e que essa relação pode ser interpretada como o desempenho de um papel subalterno da mulher em relação ao parceiro afetivo traficante. Observamos que esse envolvimento se apresenta em determinados momentos da vivência cotidiana dessas mulheres, mas que não devemos entender essa perspectiva de forma hegemônica. Ou seja, existem vários outros elementos que devemos levar em consideração quando buscamos realizar uma reflexão sobre a participação feminina na dinâmica do tráfico de drogas.

A inserção feminina no tráfico de drogas é muito mais fácil do que a inserção dessas mulheres no mercado de trabalho, constituindo assim uma estratégia de vida e sobrevivência. Quando observamos o perfil das mulheres encarceradas na cidade de Ponta Grossa - Paraná, percebemos que seu envolvimento com o tráfico de drogas acorreu primeiramente por suas próprias condições de vida. $\mathrm{Ou}$ seja, 63\% delas tinham renda inferior a R\$ 500,00 reais, baixa escolaridade - $64 \%$ têm o primeiro grau incompleto - condições essas que dificultam seu acesso ao espaço público e consequentemente ao mercado de trabalho. A questão familiar e todas as suas especificidades serão tratadas de forma mais densa a seguir.

O que defendemos é que a participação feminina na dinâmica do tráfico de drogas acontece principalmente pela situação de invisibilidade que essa população de baixa renda vive frente ao poder público. Não podemos deixar de apontar que grande parte dessas mulheres é desprovida de assistências e sem meios de garantir sua sobrevivência e de seus filhos, buscam caminhos mais fáceis, como o tráfico de drogas.

Parece desconfortável, mesmo para nós, pesquisadoras/es feministas, encontrar situações que põe abaixo a posição de vitimização das mulheres. A convivência com as presas no Mini Presídio Hildebrando de Souza nos mostrou que as próprias mulheres descartam a posição de vítima, da mulher angelical manipulada pelo homem 'mau'. Em suas falas, é comum observar que admitem que houve alguma influência por parte de amigos ou mesmo de cônjuges no seu envolvimento com as drogas, mas que ainda assim, 'caíram' por decisão própria e cientes dos riscos que corriam. Como na fala da detenta Milena':

Não é bem assim não, a gente não é nem um pouco coitadinha nem nada, o povo vem pensando que agente é coitadinha, mas não é. Quando a gente começa a mexer ali, a gente já sabe muito bem o que é, tem consciência do que é, e consciência de que pode caí à qualquer hora. Tem as influenciadas, com certeza também, mas todo mundo tá ciente do que tá fazendo. (Entrevista realizada em 24/11/2009 no Mini Presídio Hildebrando de Souza)

Quando entramos no ambiente carcerário com a informação de que muitas das mulheres que se 
encontram presas estiveram envolvidas com drogas, tendemos a imaginar uma massa homogênea de pessoas com histórias de vida muito parecidas. Contudo, percebemos que apesar da aparente homogeneidade, são as peculiaridades presentes na vida de cada uma delas que as levou à prisão, como por exemplo, suas espacialidades cotidianas e redes de relacionamentos.

Nesse sentido, Pimentel (2008b) analisou os laços de afetividade que levaram as mulheres presas no Estado de Alagoas à criminalidade e ao tráfico. A autora trabalha com a perspectiva de que o amor romântico tem grande peso, geralmente decisivo, na escolha das mulheres em entrar na dinâmica do tráfico de drogas.

A afetividade é uma condição incontestável da experiência humana, sendo supervalorizada nas vivências femininas. A sociedade ocidental é marcada por um modelo ideal de amor - paixão. Lipovetsky (2000) discute a construção ocidental do amor e conclui que mesmo com todas as posturas revolucionárias das mulheres no século $\mathrm{XX}$, esse sentimento de amor ideal permanece inabalado. Nas palavras de Lipovetsky (2000):

Nenhuma ilusão: mesmo na exaltação do período contestador, as mulheres jamais renunciaram aos sonhos de amor. O discurso sentimental se tornou eufemístico, não as experiências e os valores amorosos. O novo ceticismo em relação à retórica romântica e a sexualização dos discursos não correspondem ao recuo das esperanças amorosas mas à rejeição das convenções 'falsas', bem como à promoção dos valores de proximidade e de intimidade, à intensificação da necessidade de uma comunicação mais autêntica (LIPOVETSKY, 2000, p. 28).

A identidade feminina é construída culturalmente e marcada por determinados papéis e comportamentos sociais, os quais, a sociedade espera encontrar em uma mulher. A passividade, a gentileza e também o romantismo. As mulheres encarceradas também valorizam o amor romântico e de acordo com a perspectiva de Pimentel (2008b), também embarcam no tráfico de drogas por amor ao marido, conforme se observa na fala da detenta Vitória, de 28 anos e casada há 14 anos com o marido que também se encontra preso por tráfico de drogas:

Eu trabalhava de carteira assinada, numa granja perto da cidade. Mas daí meu marido veio pra cá e eu vim atrás dele, aí ele caiu nas drogas, eu cai nas drogas também. Tem a ver com ele sim, porque ele foi criado assim, no meio de muita briga, mãe e pai separado e ele, desde os 9 anos é usuário de droga, e tudo que eu sei, tudo que eu aprendi foi com ele (Entrevista realizada em 20/11/2009 no Mini Presídio Hildebrando de Souza).

Concordamos com Pimentel (2008b) quando a autora indica que os laços de afetividade podem posicionar as mulheres em situações de vulnerabilidade ao tráfico de drogas, entretanto, gostaríamos de acrescentar que a perda desses laços de afetividade e relacionamentos maritais tem peso fundamental na opção de se envolver com atividades criminosas e o tráfico de drogas. Podemos constatar isso nas palavras de Letícia, uma mulher presa há dois anos por tráfico de drogas:

Vivi com meu marido 12 anos, daí quando fazia um mês que eu estava separada dele eu vim presa. Eu comecei a vender quando separei dele, por causa que, ele me tirou tudo, ele vendeu minhas coisa de dentro da casa, até a cama ele me deixou sem e eu não tinha, fui aonde tava mais fácil, e acabei vindo pará aqui, já faz dois anos hoje que eu to presa. Eu usava crack, usei muito, muito crack, maconha, cocaína, o que viesse, já cheirei até cola, mas o que hoje eu to sofrendo, por causa das consequências, porque elas vêm (Entrevista realizada em 22/11/2009 no Mini Presídio Hildebrando de Souza).

Quando analisamos o papel da mulher no tráfico de drogas, percebemos que algumas ainda se encontram em posições subalternas, realizando serviços de entrega e embalagem da droga. Entretanto, algumas mulheres estão assumindo cada vez mais papéis de chefia se tornando 'donas - da - boca' após a prisão dos maridos, ou mesmo, quando são abandonadas pelos cônjuges:

Hoje em dia a gente tá vendo cada vez mais as mulher competindo com os homens, tem mulher chefiando boca e competindo. Acho que tá muito nessa competição de homem e mulher, quem ganha mais, quem vende mais droga. Não é mais só homem não, tem bastante mulher também na chefia(Entrevista realizada em 21/11/2009 
no Mini Presídio Hildebrando de Souza).

Moura (2005) estudou a participação feminina no tráfico de drogas na penitenciária feminina do Estado do Ceará. A autora observou que as desigualdades de gênero presentes no mercado de trabalho também estão presentes na dinâmica do tráfico de droga. Ela discute que $81,4 \%$ das mulheres entrevistadas em sua pesquisa, disseram ter papéis subalternos, como entregadoras, embaladoras ou fazendo uma micro comercialização, ou seja, usam uma parte de droga e a restante vendem para conhecidos. É interessante lembrar que muitas mulheres são presas na tentativa de transportar drogas para dentro dos espaços carcerários. Como diz Milena:

Eu fui leva droga pro meu marido que tá preso e me pegaram na revista. Já tinha até denuncia e tudo, de que eu vinha traze a droga pra ele, aí me pegaram, fizeram queixa de mim e me jogaram aqui. Eu não pensei, não achei que ia ser presa, se pensasse, nem tinha vindo aqui. Ele já tava preso fazia tempo mesmo, ninguém me pediu nem nada, eu trouxe porque eu quis, porque não achei que ia ser pega, ah se eu soubesse (Entrevista realizada em 24/11/2009 no Mini Presídio Hildebrando de Souza).

A população encarcerada feminina, invariavelmente pobre e com baixíssima escolaridade, encontra no tráfico de drogas um escape para sua situação de pobreza e abandono. A inserção feminina nessa dinâmica é muito mais fácil do que a inserção dessas mulheres no mercado de trabalho, constituindo uma estratégia de vida e sobrevivência. Ou mesmo, como disse Letícia: 'fui aonde tava mais fácil'.

Moura (2005) afirma que:

O tráfico de drogas passa a representar uma real estrutura de oportunidades para as mulheres, não só pela oportunidade de um retorno financeiro imediato, mas também pela predominância da informalidade do mercado e a virtual ausência de barreiras ao ingresso de mão de obra feminina nesse mercado. Alia-se a tudo isso o fato de que essa atividade remete, de alguma forma, para a esfera doméstica, espaço que as mulheres dominam e onde se identificam (MOURA, 2005, p. 126).

Gostaríamos, pois, de terminar nossa reflexão ressaltando a importância e a riqueza que a análise espacial confere a esse fenômeno. A espacialidade na qual essas mulheres vivem as coloca em situação de vulnerabilidade e apaga de suas vivências cotidianas qualquer possível sensação de estranhamento com o tráfico de drogas. Muito pelo contrário, essa dinâmica é encarada por elas como uma maneira de conseguirem seus objetivos de forma rápida, sejam eles financeiros ou não.

\section{Palavras Finais}

Hoje, a criminalidade e seus temas afins, sendo um deles o tráfico de droga, geram uma enorme inquietação, tanto na sociedade em si, como no meio acadêmico. Coelho (2005) sintetizou muito bem as dificuldades que os pesquisadores ainda encontram quando optam por se engajarem nos estudos criminológicos. $\mathrm{O}$ autor lembra que apesar da marginalidade já ser tema presente nas agendas acadêmicas, a criminalidade ainda não surgiu como um tema específico para a Academia, possivelmente, por ser considerada uma consequência da marginalidade.

Mesmo nas perspectivas feministas, a criminalidade feminina ainda permanece como tema obscuro. As/os pesquisadoras/es feministas ainda se sentem constrangidas/os por trazer à tona um tema que pode facilmente colocar em dúvida a posição angelical e vitimista das mulheres, contrariando assim, anos de tradição à demonização masculina.

Entretanto, acreditamos que com as discussões trazidas pelas Geografias Feministas podemos tornar mais rico e inteligível o fenômeno do tráfico de drogas. Apresentamos, assim, a relação que as mulheres têm com a dinâmica do tráfico de drogas. Nosso discurso não deve ser entendido de forma hegemônica, muito pelo contrário. Nossas ideias devem ser entendidas a partir de um contexto próprio, com complexidades e especificidades intimamente relacionadas com sua espacialidade.

1 Todos os nomes utilizados são fictícios e de escolha das detentas. Nosso objetivo é o de proteger a identidade das depoentes.

\section{Referências}

ABREU, Sérgio França Adorno de. "A síntese criminológica: diagnóstico e prognóstico". In: CONGRESSO BRASILEIRO DE ADMINISTRAÇÃO PENITENCIÁRIA, 1980, São 
Paulo. Anais... São Paulo, 1980. p. 55-59

BADINTER, Elisabeth. Rumo Equivocada: o feminismo e alguns destinos. Rio de Janeiro: Civilização Brasileira, 2005.

BRASIL, Ministério da Justiça. Sistema Penitenciário Nacional do Brasil. População carcerária sintética. Departamento Penitenciário Nacional. Brasília, 2001.

BRASIL, Ministério da Justiça. Sistema Penitenciário Nacional do Brasil. Dados consolidados. Departamento Penitenciário Nacional. Brasília, 2007.

BRASIL, Ministério da Justiça. Departamento Penitenciário Nacional. Mulheres encarceradas: diagnóstico nacional. Consolidação dos dados fornecidos pelas unidades da federação. Brasília, 2008.

BRASIL, Ministério da Justiça. Sistema Penitenciário Nacional do Brasil. População carcerária sintética. Departamento Penitenciário Nacional. Brasília, 2009.

COELHO, Daniel Vasconcelos . A crise no sistema penitenciário brasileiro. Disponível em: $<$ http:.neofito.com.br/artigos/ penal134.htm>. Acesso em: $12 / 01 / 2010$

DURKHEIM, Emile. As Regras Do Método Sociológico. São Paulo: Companhia Editora Nacional, 1987.

MISSE, Michel. "Crime e pobreza: velhos enfoques, novos problemas". In: VILLAS BOAS, Glaucia; GONÇALVES, Marco Antonio. (Org.). O Brasil na virada do século. Rio de Janeiro: Ed. Relume Dumará, 1995a. p. s/p.

MISSE, Michel. Cinco teses equivocadas sobre a criminalidade urbana no Brasil. Uma abordagem critica acompanhada de sugestões para uma agenda de pesquisas. Núcleo de Estudos da Cidadania, conflito e violência urbana.NECVU. 1995b. disponível em

$<$ http://www.necvu.ifcs.ufrj.br/arquivos/cinco $\% 20$ Tese s\%20Equivocadas $\% 20$ sobre $\% 20 \mathrm{a} \% 20$ Criminalidade $\%$ 20Urbana $\% 20$ no $\% 20 \mathrm{Bra} \% \mathrm{E} 2 \% 80 \% \mathrm{~A} 6$.pdf>. Acesso em: $12 / 01 / 2010$.

OLIVEIRA, Giovane Rodrigues de. "Senso comum, pobreza e criminalidade". COLÓQUIO INTERNACIONAL, (DES)ENVOLVIMENTOS CONTRA A POBREZA: MEDIAÇÕES TEÓRICAS, TÉCNICAS E POLÍTICAS. Montes Claros, 21 a 23 de agosto de 2008. Disponível em: $<$ http://www.unimontes.br/coloquiointernacional/arqui vos/118giovanerodriguesdeoliveira.pdf $>$. Acesso em: $12 / 01 / 2010$

PAIXÃO, Antonio. Luiz; CAMPOS, Edmundo Coelho. Caracterização da população prisional em Minas Gerais e Rio de Janeiro. Belo Horizonte: Fundação João Pinheiro, 1983.

PINHEIRO, Paulo.Sérgio. Crime, violência e poder. São Paulo: Brasiliense, 1983.

RAMALHO, José Ricardo. O mundo do crime. A ordem pelo avesso. Rio de Janeiro: Graal, 1976.

SANTOS, Milton. A natureza do espaço: Técnica e tempo. Razão e emoção. São Paulo: EDUSP ual de São Paulo, 2008.

SILVA, Joseli Maria. Um ensaio sobre a potencialidade do uso do conceito de gênero na análise geográfica. Revista de História Regional, v. 8 n. 1 p. 31-45. Ponta Grossa, 2004.

SILVA, Joseli Maria. Análise do Espaço sob a perspectiva de gênero: um desafio para a Geografia Cultural Brasileira. In: ROSENDAHL, Z. CORRÊA, R.L. (Org.) Geografia: Temas sobre cultura e espaço. Rio de Janeiro: EdUERJ, 2005. p. 173-187

SOARES, Barbara Musumeci; ILGENFRITZ, Iara. Prisioneiras: vida e violência atrás das grades. Rio de Janeiro: Garamond, 2002.

SOUZA, Marcelo Lopes. Desafio Metropolitano. Um estudo sobre a problemática socioespacial nas metrópoles brasileiras. Rio de Janeiro: Bertrand Brasil, 2000.

SOUZA, Simone Brandão. Criminalidade Feminina: trajetórias e confluências na fala de presas do Talavera Bruce. Revista Democracia Viva. n.33 p.10-16 outubro/dezembro 2006.

TOMASINI, Maristela Bleggi. O homem delinquente O livro que mudou o direito penal. Notas sobre Cesare Lombroso e sua obra. 2009. Disponível em $<$ http://www.scribd.com/doc/14135564/O-HomemDelinquente $>$ Acesso em: 12/01/2010.

Recebido em 14 de março de 2011. Aceito em 06 de abril de 2011. 